\title{
Article \\ Online University Students' Perceptions on the Awareness of, Reasons for, and Solutions to Plagiarism in Higher Education: The Development of the AS\&P Model to Combat Plagiarism
}

\author{
Muhammad Abid Malik ${ }^{1}$ (D), Ameema Mahroof ${ }^{2}$ and Muhammad Azeem Ashraf ${ }^{3, *(D)}$ \\ 1 Department of Education, Iqra University, Karachi 75500, Pakistan; m_abidmalik7@yahoo.com \\ 2 Faculty of Education, University of the Punjab, Lahore 54590, Pakistan; ameema.mahroof@gmail.com \\ 3 Research Institute of Education Science, Hunan University, Changsha 410082, China \\ * Correspondence: azeem@hnu.edu.cn
}

\section{check for}

updates

Citation: Malik, M.A.; Mahroof, A.; Ashraf, M.A. Online University

Students' Perceptions on the

Awareness of, Reasons for, and

Solutions to Plagiarism in Higher

Education: The Development of the AS\&P Model to Combat Plagiarism. Appl. Sci. 2021, 11, 12055. https:// doi.org/10.3390/app112412055

Academic Editor: João M. F. Rodrigues

Received: 13 October 2021

Accepted: 9 December 2021

Published: 17 December 2021

Publisher's Note: MDPI stays neutral with regard to jurisdictional claims in published maps and institutional affiliations.

Copyright: (C) 2021 by the authors Licensee MDPI, Basel, Switzerland. This article is an open access article distributed under the terms and conditions of the Creative Commons Attribution (CC BY) license (https:// creativecommons.org/licenses/by/ $4.0 /)$.

\begin{abstract}
Academic plagiarism has remained a major concern for higher education institutions, as it hampers not only the quality of the teaching-learning process and research, but also the overall educational institution. This issue appears to be even more serious in online and distance education institutions. As a result, a qualitative study was conducted on an online university in Pakistan to investigate the determinants of academic plagiarism and to find ways to address this issue. The students were given an open-ended questionnaire to reflect their opinions on the awareness and understanding of plagiarism, its determinants, and ways to address it. The findings revealed that most of the 267 online university students had a poor awareness and understanding of plagiarism. Major reasons for students' plagiarism turned out to be a lack of a proactive approach to create awareness, an omission of citation conventions from course content, untrained teachers, a lack of strict penalties and their proper implementation, poor time management, a fear of failure, a lack of confidence, laziness, and a culture of plagiarism. The study proposes the Awareness, Support, and Prevention model (AS\&P model) to address this issue in higher education institutions.
\end{abstract}

Keywords: plagiarism; ethics; academic dishonesty; online education; higher education; AS\&P model; Pakistan

\section{Introduction}

Although there is no universally accepted definition of plagiarism [1,2], as it is culturally and socially influenced [3], it may be taken as a type of fraud, where someone takes others' ideas or work and presents it as one's own [4]. The 7th edition of the APA (American Psychological Association) publication manual describes plagiarism as "the act of presenting the words, ideas, or images of another as your own" [5].

There are different types of plagiarism, and different ways in which a person may plagiarize [6]. Academic plagiarism is one of those types, which is done within academic work or assignments. Lathrop and Foss said that academic plagiarism occurs when one does not think or write by oneself, or does not give appropriate bibliographical references [7]. It is generally detected through similarity index software such as Turnitin or Urkund [8].

Academic plagiarism is considered unethical in academia, as it not only damages the overall quality of education, but also compromises merit. As a result, it often invites punitive and disciplinary actions from higher education institutions and regulatory bodies. Unfortunately, despite those disciplinary policies, preventive measures, and punitive actions, plagiarism continues to grow, especially in higher education [8,9]. One of the reasons for this may be the availability of modern tools and software that allow students to search relevant materials on the internet and other online sources with relative ease $[10,11]$. Increasing access to rephrasing software further adds to this issue. In this situation, 
educational institutions are forced to allocate a substantial amount of time, effort, and resources to address it [12]. Students' lack of awareness and understanding of plagiarism is another important reason. Bennett found that many students did not know the correct citation conventions that could lead them to unintentional plagiarism [13]. Fish and Hura echoed this, saying that the students who lacked clarity about plagiarism and its consequences were more likely to commit it [14].

The literature also mentions many other reasons for plagiarism. Some of them are a lack of awareness, language issues, a tight schedule and deadlines, teachers' attitudes, high competition and expectations, a fear of failure, and peers' influence [13,15-21]. Different types of pressures have also been pointed out as contributing factors [22-24]. Songsriwittaya et al. [25] mentioned students' desire to obtain high marks, exam pressure, and stiff peer competition as the most important reasons. Time-related issues are also quite significant, as students often have to complete assignments and other tasks in a limited amount of time [2].

Another reason for plagiarism is the difficulty of tasks. Weak preventive and disciplinary actions and/or a lack of policy enforcement may also tempt the students to plagiarize. Harris [16] (p. 6) supported this by saying, "cheating in self-defence may appear rational in a highly competitive atmosphere, especially where students believe there are few operative punishments".

Plagiarism is also a serious issue in Pakistan [26-28]. Previous studies have revealed that most of the students are either unaware about it [29] or have a poor understanding [30]. Murtaza et al. [29] carried out a study investigating Pakistani university students' awareness and perceptions about plagiarism. They collected data from 25,742 students from 35 universities in Pakistan. The findings revealed that $94 \%$ of the participants were not aware of the plagiarism policy of the HEC (Higher Education Commission). Another study found that many students did not know about their own university's policies about it [30]. The education and training of the students about plagiarism and citation conventions are also generally overlooked. Fatima et al. found that students' lack of a proper education and training about plagiarism and an inadequate skillset were two of the most significant factors [8]. Apparently, the HEC and higher education institutions in Pakistan have failed in their responsibility to create an awareness and understanding of plagiarism and its policies. As a result, plagiarism continues to thrive in Pakistan.

Recent decades have seen a rapid growth of online and distance education across the world [31-33]. Although there have been quite a few studies about plagiarism amongst online and distance education students [34,35], such research about Pakistan is quite rare. Additionally, research about online university students is also quite limited. The current study tried to fill some of these research gaps by focusing on the students of the only online university in Pakistan. It had three main research objectives:

- To investigate the awareness and understanding of plagiarism among online university students;

- To find out the perceptions of online university students about its determinants;

- To provide suggestions on how to address the issue.

\section{Materials and Methods}

\subsection{Research Method and Tool}

The current study used a qualitative research approach to achieve the research objectives. The rationale for employing qualitative research is that it allows in-depth data gathering from the participants [36]. At the same time, there was a desire to collect data from a larger number of participants in a way where they could freely and independently express their thoughts; consequently, an open questionnaire was selected as the research tool. One can gather in-depth data from a large number of participants through an open questionnaire [36]. However, the drawback of this technique is that one cannot ask supplementary questions for further probing. Doró also used a similar technique (asking students to write a one-page opinion essay on plagiarism) for data collection [2]. 
In order to collect data, the students were sent three main questions through their official emails. Every question was further explained in parentheses for clarity. Those questions were, "What is plagiarism (understanding and awareness about the concept)?", "Why do you think the students plagiarize (reasons behind it)?", and "How can we address this issue (suggestions to control plagiarism)?". The email also included the aims and scope of the study and a consent letter for voluntary participation. The students were asked to send their responses in 10 days. Those who did not respond within that time were reminded again twice every 15 days.

There were no word limit requirements to write reflections, and the participants were encouraged to elaborate as much as possible. They were asked to send their responses in MS Word files so that the researchers could directly use them in NVivo.

To ensure research ethics, permission was granted from the university to conduct the study. All the participants were asked to sign a consent letter for their voluntary participation. They were clearly told about the purpose of the research and that their participation was voluntary. They were also assured of their anonymity and that their reflective writings would only be used for research purposes.

\subsection{Population and Sample}

Data were gathered from an online university in Pakistan. This university is the first completely online university in the country. The students belong to three different departments (management sciences, computer science, and education) in both undergraduate and graduate programs. They were contacted through their university emails. Data were collected from the students studying during the Fall 2019 semester (October 2019-March 2020). During that semester, there were 14,743 active students in the university receiving virtual education. An email including the aims and scope of the study and a consent form for voluntary participation was sent to the students. A similar email was sent to the students twice every 15 days. Following the guidelines provided by the literature [37-39], the data analysis phase started as soon as the sample size of this study was considered appropriate for data analysis. In total, 300 students replied to the email to show their interest in participating the study. However, 267 participants filled the questionnaire and submitted it the authors.

Among these 267 students, 159 were male, and 108 were female. As it is an online university with many students working full time, their age ranged widely (19-52) with a mean age of 26 years, and $71 \%$ of the participants were from urban areas, while $29 \%$ were from rural areas.

\subsection{Data Analysis Technique}

The data were analyzed through qualitative data analysis software Nvivo 11. Initially, all data were imported into Nvivo. The researchers read all the writings one by one to search for broader themes and categories. Later, Nvivo was used to create codes and themes. Data visualization was also used for the determinants. In total, Nvivo generated 22 themes for determinants. The researchers again looked into those themes and grouped them into five broader categories.

Verbatim quotations were also used frequently, as they help in conveying the feelings and emotions of the participants more clearly and forcefully [40,41]. Two of the researchers independently selected significant verbatim quotations. They were later discussed by all three researchers. More significant and relevant ones were retained and reported in the article.

Frequencies and percentages were also used to present the data more clearly.

\section{Results and Discussion}

This section contains data findings and discussion. Other than background information, data analysis was carried out on three different lines: the awareness and understanding of online university students about plagiarism, their perceptions about its determinants, 
and how it can be addressed. These findings were further interpreted and discussed in light of the literature.

\subsection{Online University Students' Awareness and Understanding of Plagiarism}

The first question that the students were asked to write about was focused on their awareness and understanding of plagiarism: what was plagiarism to them? In order to establish how relevant and appropriate students' awareness and understanding of plagiarism was, it was important to first take one definition as the standard. After reviewing the literature, the researchers decided to use the definition in the 7th edition APA publication manual [5] as a standard because of its clarity, comprehensiveness, relevance, and significance. It is also used widely in most of the universities in Pakistan and abroad. It has three important components: (i) copying or lifting text, (ii) using not only words but also ideas of other authors, and (iii) presenting work as your own (not citing the original work properly). When a student showed a limited idea or understanding of plagiarism, but not the whole idea (e.g., using only the term "copy and paste"), it was categorized as a poor/incomplete understanding.

The analysis of students' responses showed that out of 267 students, only 41 (15.36\%) could define it properly. The rest either had a completely wrong idea about plagiarism ( $n=37,13.86 \%)$ or an incomplete idea $(n=189,70.79 \%)$.

An overwhelming majority (41\%) used the term "copy and paste" to describe plagiarism. Other terms used by the students were "copy" $(26 \%)$, "cheating" (15\%), "writing without citations" (11\%), and others (7\%). Among others, "stealing others' ideas", and "presenting others' work as your own" were prominent terms used by the students. One student wrote, "... [If I] copy something and then paste it in my assignment, then it is plagiarism". Another wrote, "Plagiarism is copying many lines from [the] Internet". Some of the students" understanding of plagiarism appears to be defined by how different software is used to work to check plagiarism. They mentioned lifting five consecutive words as plagiarism. These students did not seem to realize that plagiarism was not only copying and pasting the text, but also using others' ideas without giving proper credit to them. Some did not see that copying and pasting could be academically ethical if it is cited properly.

The literature also points out that most of the students do not have a proper awareness and understanding of plagiarism [42] and citing conventions [13,43]. This shows that, if students do not know the meaning of plagiarism, it is difficult for them to avoid it. There seems to be either an inability of the universities to increase awareness and understanding or an unwillingness of the students to learn about it.

\subsection{Why Do Students Plagiarize?}

The second question was related to the determinants of plagiarism. Based on the responses of 267 students, Nvivo generated 21 themes (Figure 1). These themes were reported 421 times by the participants.

The researchers investigated the themes and grouped them into five broader categories: a lack of awareness and a poor understanding of plagiarism, weak management of the education system and institutional issues, academic pressures and barriers, personal and psychological reasons, and plagiarism becoming a trend. The details of these categories and their themes are as follows. 


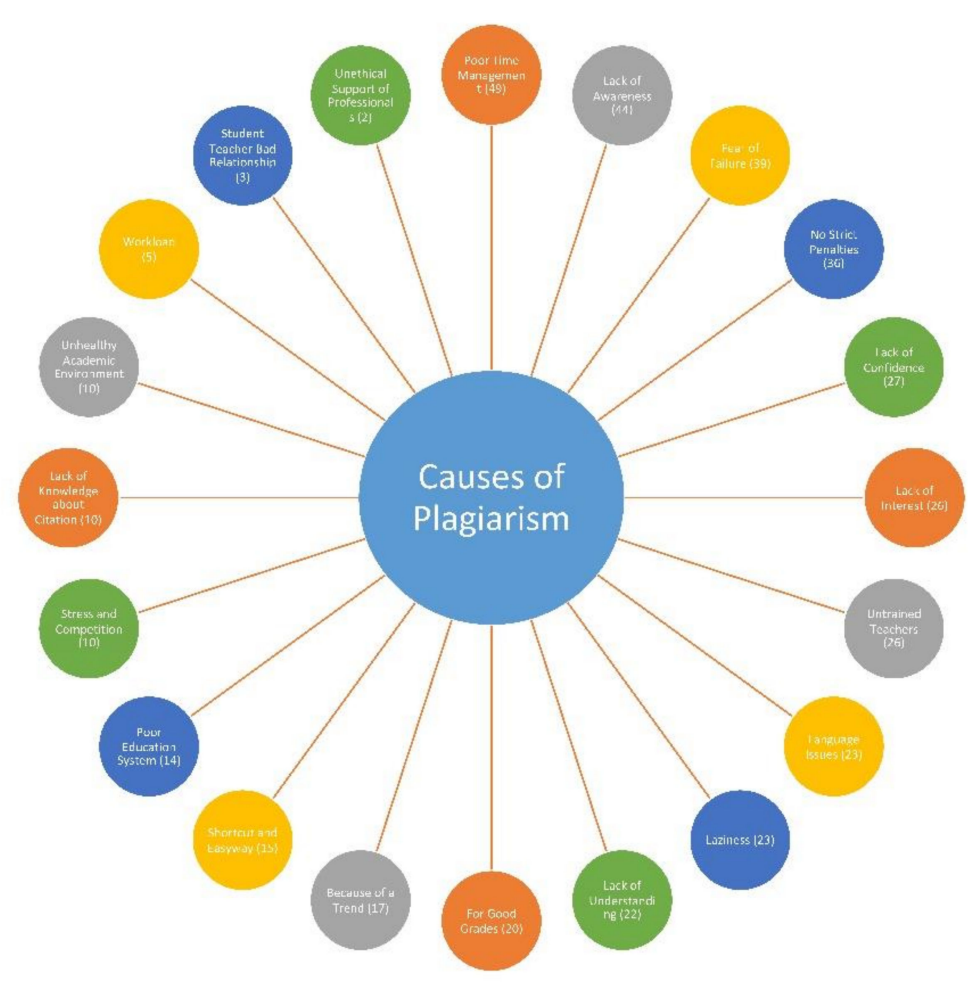

Figure 1. Determinants of plagiarism.

\subsubsection{A Lack of Awareness and a Poor Understanding of Plagiarism}

The most basic and fundamental cause seems to be the students' lack of awareness and understanding of plagiarism. Three Nvivo-generated themes were placed into this category: a lack of awareness, a poor understanding, and a lack of knowledge about citations.

The first theme was a lack of awareness, as 44 students wrote that they had a lack of awareness of plagiarism and the policies about it. Despite being university students, they said that they had not even heard about it. Their awareness about plagiarism, plagiarism policies, and the consequences of plagiarism was very limited. As one student wrote,

“... . (In Pakistan) most students are unaware about plagiarism and its consequences.

No one tells them about it. We do not find it anywhere. Some students [do not even]

know the meaning of plagiarism. So most students are doing plagiarism without even knowing that they are doing plagiarism."

This situation is not surprising, as the literature also points this out $[29,30]$. Surprisingly, these are online university students who are more Internet savvy. The university has also provided information about plagiarism on both its website and the LMS (learning management system), but it seems that no proactive measures were taken to create an awareness of it.

The second theme in this category was a poor understanding of the concept. Twentytwo students said that the students did not have a proper understanding of the concept. This can also be connected with their responses to the first question, where the majority of students said that plagiarism was "copy", "copying", or "copy-paste" only. This confirms [42] (p. 643) the notion that students are "still apparently confused" about the concept of plagiarism.

The third theme was focused on students' knowledge about practices to avoid plagiarism, especially citation conventions. More than half of the students (149 out of 267) reported that they were never taught about plagiarism or citation conventions at any level. They stated that their lack of knowledge often led them to plagiarize content, even when they tried to avoid it. As one student wrote, 
"... in citations and references ... finding [the] right content and right method for citation[s] is [the] biggest problem. Many students do not know how to cite, how many words should be in inverted commas, [or] how to give reference[s]. Most of the time we think we [have] cited correctly, but in reality we [have] not, and we [have committed] plagiarism."

Another student explained how the lack of proper guidance about citations could play a role, saying,

"We [were] never taught about references and citations. There was no course in college, [or] even in university, [and] we do not have any course on this topic. Maybe [the institution and faculty] think that it is easy and we can learn by ourselves. But it is difficult. It is very difficult."

Many studies have also pointed this out $[13,43]$. Often institutions think that citation conventions can be learned by the students themselves; however, in reality, citations and reference lists are quite difficult and confusing and should be taught properly.

These findings show the alarming situation of online university students' awareness and understanding of plagiarism in Pakistan. More than one fourth of them (76 out of 267) indicated their lack of awareness and a poor understanding of plagiarism and citing conventions, which has been a recurring theme in the literature [13,29,42]. Although the students had some idea about their own abilities and knowledge (or the lack of it) about plagiarism, it might be possible that many students are simply unaware about their lack of awareness. They might think that they know what plagiarism is, but their knowledge could be either completely wrong or incomplete.

\subsubsection{Weak Management of the Education System and Institutional Issues}

The second category that emerged from the data was the weak management of the education system and institutional issues, which either encouraged students to plagiarize or failed to prevent them from doing so. This category consists of six Nvivo-generated themes, i.e., a poor education system, an unhealthy academic environment, the unethical support of professionals, untrained teachers, a negative relationship between teachers and students, and a lack of strict penalties.

Fourteen students indicated a poor education system. Rather than pointing out any specific issue, they blamed the overall education system of the country. According to them, the blame goes to the overall educational system and culture in the country. These perceptions are similar to the authors in [44] who pointed out the academic and research culture in Pakistani higher education. One student expressed it in these words: "[The] education system is poor. Problems are everywhere. Everything is bad". Another student echoed the same opinion, writing, "It is difficult to blame one thing[;] everything in [Pakistani] education is bad".

In addition, six students put the blame on an unhealthy academic environment. One wrote, "... students who try to follow rules [and be] honest in academics suffer". Similarly, talking about the academic environment in the university, another student wrote, "It's [a] poor academic environment. We are not taught well, [as there are] just recorded lectures. No further explanation [required]". According to this student, as the students were not taught properly, they chose to plagiarize. Many students said that much greater efforts are needed in an online university to develop a strong academic culture that, to prevent such unethical practices, promotes not only academics but also moral values. Some researchers also indicated that online university students were more inclined to plagiarism [45].

Students also talked about the role of university personnel, especially faculty members, a negative relationship between teachers and students, and unethical support from professionals. Some students wrote that untrained teachers were key in the fast spread of plagiarism in Pakistan. The students mentioned that most of their teachers did not know about plagiarism, especially the proper meaning of plagiarism. One student expressed his personal experience as, "My teacher said you should not write five consecutive words so 
most of us lifted the text and then rephrased every fourth or fifth word. I later found that it was still plagiarism".

In addition, students mentioned "untrained and nonprofessional" research supervisors, who actually encouraged the students to commit plagiarism. One student wrote that his supervisor advised him to copy and paste the literature review and later use word rephrasing software to rephrase it. The students also reported unethical support from professionals and other office staff. A few students wrote that some teaching assistants and office staff would help the students in obtaining fake plagiarism reports.

Three students mentioned a negative teacher-student relationship. They pointed out that some teachers had a very aggressive and hostile attitude toward the students, and students did not feel comfortable asking them any questions. However, the standards and requirements of courses taught by those teachers were very strict, which compelled the students to plagiarize in order to produce "quality work". Howard also advocated that, rather than policies, educational institutions should focus on positive teacher-student relationships to eliminate plagiarism [46].

Another theme that stemmed from students' writings was a lack of strict penalties for plagiarism. Thirty-six students wrote about it and described how the students committing plagiarism often got away with either a simple warning or a lighter punishment. One student wrote, "Penalties are flexible. Even though students are well aware of plagiarism, they still plagiarize and think they have [fewer] chances of being caught." Another student further explained it in these words: "Often professors just scold [students who plagiarize], [saying things] like 'shame on you' or 'do it again,' and that is it. Many times students [are] not caught". One graduate student summed it up in these words, "Soft penalties encourage students to plagiarize again and again".

Researchers have been consistently vocal about the lack of penalties or light penalties for plagiarism as one of the key reasons for plagiarism [30]. In this situation, when students weigh in threats and benefits, they often find it worth taking a risk [16].

This clearly indicates that academic and nonacademic faculty members, education institutions, and even the overall education system in Pakistan is ill-equipped and ill-trained to address this issue. There also appears to be an issue with some of the teachers' attitudes, professionalism, and integrity. These factors along with the teachers' and universities' lenient approach toward plagiarism seem to have created an environment that is highly conducive to it.

\subsubsection{Academic Pressures and Barriers}

The most significant category was about different types of personal and academic pressures, and different barriers. These themes were mentioned by 140 students. These pressures and barriers appeared to force the students to plagiarize, as they could not manage or find a solution. This category contained six themes generated with Nvivo: poor time management, workload, stress from competition, a fear of failure, a desire for good grades, and language abilities.

Poor time management was the most frequently cited reason, as 49 students mentioned it. Time management substantially affects students across the world [47]. Many students have plagiarized to save time for other activities [2]. According to the participants, many students either wasted their time on other activities, or they simply could not manage their time properly. Therefore, they chose to plagiarize, as it would take less time to complete their work. One student wrote, " ... poor time management skills [will] in turn leave [students with] no choice [but] to cheat or plagiarize".

Another participant described the students' attitude in these words,

"They do not manage their time very well and handle situations poorly. They focus on their [assignments] at [the] last moment [and work over a] very short time[;] it is very hard for students to do excellent work. So they try to get material online and finish their tasks." 
Another determinant mentioned by five students was workload. Students said that their academic workload was too much to handle, so in order to manage heavy workload, they had to plagiarize. This has also been found in the literature [48]. Two students further indicated that a heavy workload was also related to time management. One student wrote that, even if they work hard, they cannot finish their workload on time. They had to cheat.

Sixty-three students mentioned stress from competition (10), a fear of failure (33), and a pressure to receive grades (20). This is understandable, as the education system in Pakistan measures students' performance in terms of marks and exam scores [49]. Those who receive higher marks tend to thrive in their professional life. This forces the students to aim for higher marks rather than cultivate their abilities. In order to compete with their fellow students, and to meet the required standards, some students decide to plagiarize. One student wrote, "There is tough competition ... we have to get high marks, [and that is it]." Many students admitted that, in higher education, the fear of failure was one of the more important determinants for plagiarism. One of them wrote, "If a student does not pass in an exam, people make fun of him. It is [shameful] for [a] student to get low grades. Many are afraid to fail. So they find other ways [such as] cheating to pass." The literature also indicates the stress of competition, a fear of failure, and a pressure to receive good grades as more significant factors $[13,15,18]$.

In addition to the themes mentioned above, 23 students mentioned the language barrier as one of the determinants. This seems to be a serious problem in countries such as Pakistan, where the language of the curriculum, instructions, and examinations is different from the daily language of communication [50]. This points to the fact that mostly books, assignments, and exams are in English. However, students communicate with each other in Urdu (the national language of Pakistan) or in a regional/ethnic language. As one student wrote, "Students face difficulty in translating their thoughts from their mother tongue to English. So they use [a] 'copy-paste' method. It is not because we don't have ideas or knowledge [; rather,] it is because many cannot write their ideas in English." English language writing is especially troublesome for nonnative speakers [50-52]. While conducting a study about Japanese students, Wheeler also found that a foreign-language-induced fear of failure was one of the main causes for plagiarism [53].

\subsubsection{Personal and Psychological Reasons}

Five Nvivo-generated themes were placed in the category of personal and psychological reasons. These themes were a lack of confidence, a lack of interest, laziness, looking for shortcuts and easy ways to finish their tasks, and the availability of the internet. These were identified by 27, 26, 23, 15, and 10 students, respectively.

A lack of self-belief and confidence is one of the more significant reasons for plagiarism [43]. Twenty-seven students echoed this, saying that, sometimes, the students were unsure of their own abilities and talent. They lacked confidence and self-belief, which would lead them to find alternative ways to finish their tasks. Sometimes, the lack of confidence is not due to academic problems, but to personal issues. One student wrote, "Some students do not have confidence. They think others work better than them, [so] they chose to plagiarize." Another student described it in these words, "Some students are in a complex [situation, are afraid,] or have low confidence that they cannot write [a] good piece of text and feel hesitation, so they copy and paste in [their] assignments and other work."

Twenty-six students identified the students' lack of interest as one of the key reasons. One student wrote, "Often there is time. Students are active. But they don't have interest in the studies." Another student said that many of those students who would plagiarize were quite active and smart. They had ample time to finish their tasks, but they would do other things. He wrote emphatically, "They are more clever [and] more active. They find ways to cheat the teachers. It is not easy. They could do [a] better job in writing assignments, but they find no interest in writing [on] their own."

Research about plagiarism shows that students often lacked interest in the given tasks. These students, due to their laziness, their disinterest, or other reasons, would look for 
shortcuts and easy ways to complete the task. Many students acknowledged that one of the causes of plagiarism was sheer laziness, as supported by the literature [52]. One student wrote, "Often there is time, but students are lazy. They don't want to work." Another student also reported that "many students want to complete assignments [and receive] good marks, but they do not want to work. Plagiarism is an easy option for such students."

Fifteen students said that many would plagiarize because they regard it as a quick and easy way of completing academic assignments and tasks. They did not specify if their desire to complete tasks in an easy way was due to laziness, a lack of interest, a lack of confidence, or an unavailability of modern tools. As a result, it was regarded as a separate theme.

The last theme in this category is the availability of the internet and other modern tools. Ten students cited the availability of the internet and other online tools and resources as one of the determinants in the spread of plagiarism. Multiple articles also indicate this $[10,11]$, as modern tools and technologies help the students not only to find the relevant materials more easily but also to rephrase them to avoid detection. One student pointed this out, writing, "[The] Internet has made writing easy. Students can find materials. Some software can rephrase it. It is not easy to catch them." This leaves teachers and supervisors in a difficult situation. Until and unless these educators have read the original article and remember it clearly, it is difficult to catch this type of technologically savvy cheating.

\subsubsection{Plagiarism Is Becoming a Trend}

Seventeen students wrote that plagiarism had become a trend in Pakistan. They mentioned that, due to other determinants such as the lack of awareness and understanding, teachers' attitudes, and the institutional failure to pay attention to the relevant details, plagiarism was deeply rooted into much of the education system in Pakistan. This is very similar to what Horváth said about Hungary, that plagiarism was ingrained into the Hungarian education system [54]. It also appears to have become a routine for students. One of them wrote, "No one [cares] about it. It is a trend. It is normal."

This indicates that when systems fail to highlight an issue or to proactively try to eradicate it, with the passage of time, the issue may become part of people's lives and the general culture. Once that happens, people may no longer care about it. In other words, it becomes an acceptable evil. Worse still, it may become so common that some people may start bragging about it instead of feeling ashamed of their wrongdoing. One student said the same, "It is trendy [;] many students do not feel shame. They tell others proudly." This is a worrisome, deplorable situation that demands immediate measures and actions.

\subsection{Addressing the Issue of Plagiarism}

The last question was focused on how plagiarism in higher education settings in Pakistan can be prevented. The responses from the participants were coded into different categories, and themes were generated from the codes and categories. Three major themes that were considered important by the participants to combat plagiarism in higher education, i.e., awareness, support, and prevention, were established. Previous studies have also discussed these steps to control plagiarism $[13,17,30,53,55]$. This model integrates them with other details. Thus, the themes generated from the data from the current study and from previous literature with a similar scope guided the authors to develop the AS\&P Model-the Awareness, Support, and Prevention Model (Figure 2).

The first dimension of the AS\&P model is awareness, which represents the "what" part of the problem. It is about creating awareness about all the important "whats" relating to it (What is plagiarism? What are regulatory bodies and university policies and practices saying about it? What are its consequences? What are citation conventions?). The findings of the current study show that there is an acute lack of awareness about different aspects of plagiarism. The same has been noted in earlier studies [30]. Students strongly criticized the current approach of the universities, as one student wrote, "Putting policies on [a] website and 
sitting [back without telling students about it] will not [create] awareness. [Universities] should reach [out] to the students [and] be active."

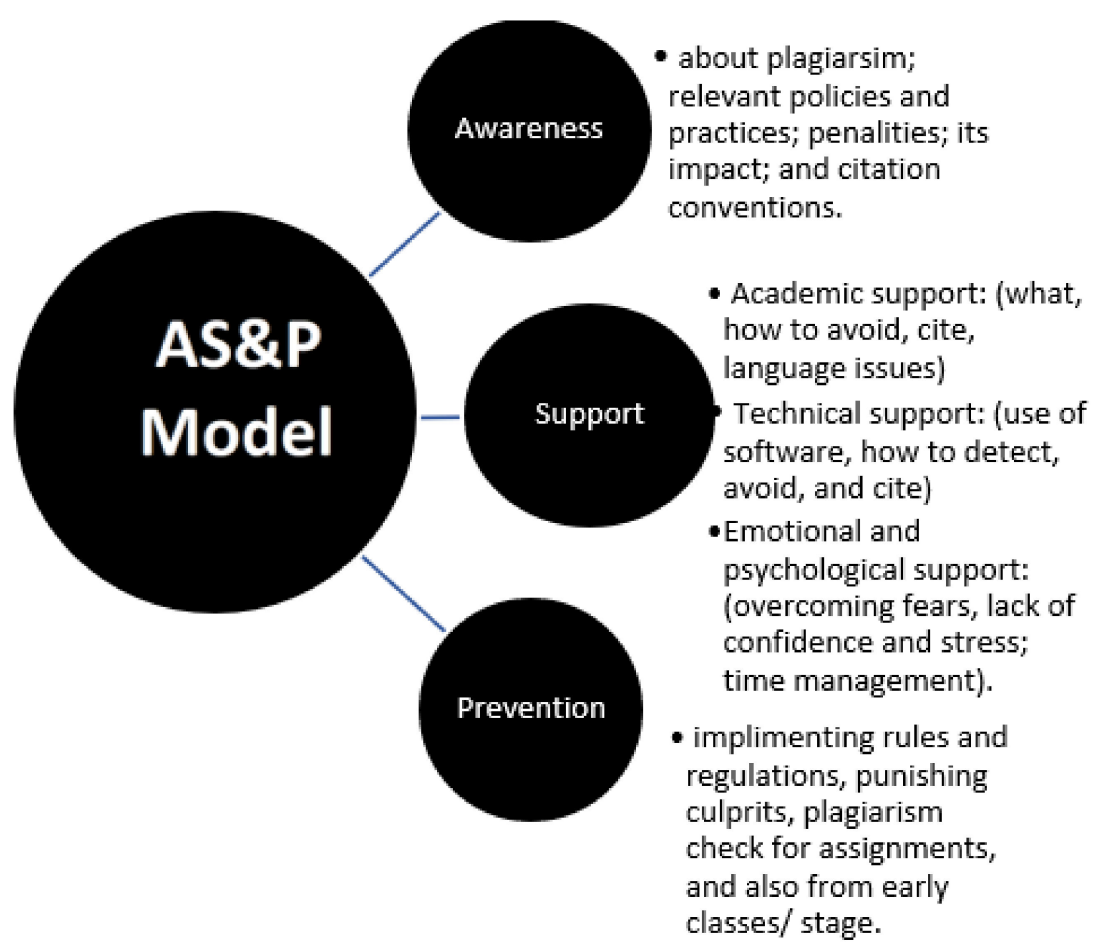

Figure 2. AS\&P (Awareness, Support, and Prevention) Model.

As a lack of awareness has proven to be one of the most significant issues in this regard $[13,42]$, many of the students recommended workshops, seminars, and training sessions to create an awareness and understanding of plagiarism. Interestingly, some of the students suggested that these workshops and training sessions should not be for the students only, but also for teachers. One student explained it, saying, "When teachers know what [plagiarism is], they can guide students better." They also suggested it be made a part of their course outlines.

The second dimension of the model is support, which represents the "how" part of the problem. Students wrote that supportive measures should be for both teachers and students. The different kinds of support suggested by the students have been divided into three categories: academic, technical, and emotional and psychological. In academic and technical support, the focus should be on the use of relevant software, how to detect and avoid plagiarism, and how to cite properly. Many of the students said that there should be support for language issues as well. One graduate student wrote at length about it, saying,

"[Universities] think [that the English of M.Phil students is good and that they] can write good English, but many cannot. We have [an] academic writing [program], but we don't do any practice; [ it only consists of ] lectures and information. It doesn't improve [one's] English. Universities in Pakistan should have special courses, [sessions] or workshops [to help students] in writing."

One student suggested that there should be a co-supervisor or member supervisory committee for language improvement. This person could help the students to improve their academic writing. Supervisors can focus on the technical and academic aspects, and the co-supervisor can focus on the language issues. In this way, the students could feel more comfortable with writing and avoid copying.

The students strongly suggested emotional and psychological support, as many of the determinants of plagiarism are related to emotional, psychological, and other nonacademic issues, such as a fear of failure, poor time management, laziness, and a lack of 
interest $[2,15,52,53]$. As a result, a positive attitude, counselling, and support from the universities, especially the teachers, are imperative to overcome these determinants. Leask very rightly pointed out that the prevention of plagiarism must not be seen as a war between academic staff and students, but as an opportunity for intercultural interactions and growth. He further said that preventing plagiarism therefore needs to be based on the principles of good teaching [55]. It was further suggested that rather than scolding the students for poor work, teachers should provide them with academic support and help in building confidence and gaining knowledge. Bashir and Malik also said that caring behavior exhibited by teachers in the classroom can help students not only with academic improvement, but also psychological, ethical, and moral improvements, which can lead to positivity and motivation amongst those students [56]. Some students also wrote about more active roles in student counseling centers in overcoming those psychological barriers. All these steps can greatly reduce the aforementioned emotional and psychological issues that have been some of the key factors of plagiarism.

The last dimension of the model is prevention. Despite creating awareness and providing supportive measures for students, some may still opt for foul play and cheating. Thus, the last dimension becomes pivotal. Universities must develop strict policies about plagiarism and enforce them in an active manner for both teachers and students. Students committing plagiarism and teachers involved in fostering plagiarism should be handled such that others will be deterred from that behavior. Most of the time, students plagiarize when they find that the benefits outweigh the risks [17]. If the risks (e.g., the punishments) are greater than the benefits, students are more likely to stay away from it.

Along with punitive actions, universities must also provide teachers with access to modern plagiarism-detection software to prevent plagiarism. Institutions should make software use mandatory for students' assignments, as well as for research work. Some students wrote that there was no culture of using plagiarism-detecting software for students' assignments or even research proposals. As one post-graduate student wrote,

"Even [for a] synopsis (research proposal), many students copy and paste, and they [pass]. Students don't worry about plagiarism at early stages, [in class assignments, course papers, or synopses] and then they are asked to come up with original work at thesis writing. It is not fair. Nobody cares about plagiarism and then suddenly they expect us to produce original work when thesis work starts. [Universities] should check [for] plagiarism all the time so that students learn about it, and are careful about it."

The AS\&P model appears to be quite comprehensive in eliminating or at least mitigating plagiarism in three different ways: creating awareness, providing support, and taking preventive measures. These measures are not only for students, but also for teachers. Plagiarism has become quite a menace in the current era, and it can only be controlled through a comprehensive approach.

\section{Conclusions, Recommendations, and Implications}

As indicated in the literature of other countries, the findings of the study confirm that plagiarism continues to remain a challenge at the higher education level in Pakistan. The findings of this study identify various determinants, such as an omission of citation conventions from course content, a lack of a proactive approach to create awareness, untrained teachers, a lack of strict penalties, poor time management, a fear of failure, a lack of confidence, laziness, and a culture of plagiarism. The students also questioned the role of universities and teachers, which ranged from reactive and laidback to promoting plagiarism. All of these factors appear to have created a culture of plagiarism in Pakistan.

Based on the suggestions given by the students, and consulting the literature on the same issue; this study provides a theoretical model, i.e., the AS\&P model (Awareness, Support, and Prevention), to address this issue. There is a strong need to adopt a more proactive approach to create an awareness and understanding of plagiarism, the policies about it, and its consequences. Universities must first educate and train their teachers about it. Later, the students should be educated through seminars, workshops, and training 
sessions. Plagiarism and citing conventions should also be made a part of different course outlines. The students should be provided with support to combat different academic, technical, psychological, emotional, and other nonacademic issues, which often lead them to plagiarize. Teachers should adopt positive and caring behavior so that students can share their issues freely and seek solutions. Finally, both universities and teachers should adopt a zero-tolerance policy for it. Students and teachers involved in this practice should be punished so that others will be deterred. Plagiarism should also be checked for in students assignments and research proposals/synopses so that they can learn to avoid it in early stages of the university career. It is worth mentioning that this model has been developed based on research findings and has not been tested in practice. Thus, researchers are encouraged to further investigate the experimental effectiveness of this model in reducing plagiarism in higher education settings.

Although this study is exclusively about Pakistan (more specifically about an online university in Pakistan), it has far-reaching implications. This model can be used in other countries, especially developing ones, with a similar context, a similar education system, and the same issues. Based on this model, universities can devise specific steps and strategies to reduce plagiarism and can emphasize different aspects of the model based on their context, issues, and needs.

\section{Limitations and Further Research}

The current study used an open questionnaire as a research tool. Although it helped in gathering qualitative data from a large number of participants, many statements made by the students required further explanation, and further probing through supplementary questions was not possible. Another qualitative study may be conducted using semistructured or open interviews to probe this issue deeper.

Furthermore, it may be interesting to compare the causes of plagiarism between students studying online and students using a more conventional mode, as students in these two groups may hold different attitudes and mindsets in regard to plagiarism.

Finally, the study has devised the AS\&P Model based on the literature and research findings. This model is theoretical and untested. It should be carefully implemented in an education system or universities to determine its effectiveness in reducing plagiarism. Therefore, future studies should experimentally investigate the effectiveness of this model in combating the issue of plagiarism in higher education.

Author Contributions: Conceptualization, M.A.M., A.M. and M.A.A.; methodology, M.A.M.; software, A.M.; validation, M.A.M., A.M. and M.A.A.; writing-original draft preparation, M.A.M.; writing-review and editing, A.M. and M.A.A. All authors have read and agreed to the published version of the manuscript.

Funding: The research received no external funding. The APC was funded by Research Funds for the Central Universities (Hunan University) in China, (Grant No. 531118010283).

Institutional Review Board Statement: This study was conducted according to the guidelines of the Declaration of Helsinki and approved by the Ethics Committee of Iqra University.

Informed Consent Statement: Written informed consent has been obtained from the participants.

Data Availability Statement: The data are available from the corresponding author at reasonable request.

Conflicts of Interest: The authors declare no conflict of interest.

\section{References}

1. Jameson, D.A. The ethics of plagiarism: How genre affects writers' use of source materials. Bull. Assoc. Bus. Commun. 1993, 56, 18-28. [CrossRef]

2. Doró, K. Why do students plagiarize? EFL undergraduates views on the reasons behind plagiarism. Rom. J. Engl. Studies 2014, 11, 255-263. [CrossRef] 
3. $\mathrm{Hu}, \mathrm{G} . ;$ Lei, J. Investigating Chinese University Students' Knowledge of and Attitudes toward Plagiarism from an Integrated Perspective. Lang. Learn. 2012, 62, 813-850. [CrossRef]

4. Badke, W. Give Plagiarism the Weight It Deserves. Online 2007, 31, 58-60. Available online: https://www.researchgate.net/ publication/292790712_Give_plagiarism_the_weight_it_deserves (accessed on 1 December 2021).

5. American Psychological Association. Publication Manual of the American Psychological Association, 7th ed.; American Psychological Association: Washington, DC, USA, 2019.

6. Ercegovac, Z.; Richardson, J.V. Academic dishonesty, plagiarism included, in the digital age: A literature review. Coll. Res. Libr. 2004, 65, 301-318. [CrossRef]

7. Lathrop, A.; Foss, K. Student Cheating and Plagiarism in the Internet Era: A Wake-Up Call; Libraries Unlimited: Englewood, CO, USA, 2000.

8. Fatima, A.; Sunguh, K.K.; Abbas, A.; Mannan, A.; Hosseini, S. Impact of pressure, self-efficacy, and self-competency on students' plagiarism in higher education. Account. Res. 2020, 27, 32-48. [CrossRef] [PubMed]

9. Jereb, E.; Urh, M.; Jerebic, J.; Šprajc, P. Gender differences and the awareness of plagiarism in higher education. Soc. Psychol. Educ. 2017, 21, 409-426. [CrossRef]

10. Comas-Forgas, R.; Sureda-Negre, J. Academic plagiarism: Explanatory factors from students' perspective. J. Acad. Ethics 2010, 8, 217-232. [CrossRef]

11. Chang, C.M.; Chen, Y.L.; Huang, Y.; Chou, C. Why do they become potential cyber-plagiarizers? Exploring the alternative thinking of copy-and-paste youth in Taiwan. Comput. Educ. 2015, 87, 357-367. [CrossRef]

12. Gullifer, J.; Tyson, G.A. Exploring university students' perceptions of plagiarism: A focus group study. Stud. High. Educ. 2010, 35, 463-481. [CrossRef]

13. Bennett, R. Factors associated with student plagiarism in a post-1992 university. Assess. Eval. High. Educ. 2005, 30, 137-162. [CrossRef]

14. Fish, R.; Hura, G. Students' perceptions of plagiarism. J. Scholarsh. Teach. Learn. 2013, 13, 33-45.

15. Franklyn-Stokes, A.; Newstead, S.E. Undergraduate cheating: Who does what and why? Stud. High. Educ. 1995, 20, 159-172. [CrossRef]

16. Harris, R. The Plagiarism Handbook; Pyrczak Publishing: Glendale, CA, USA, 2001.

17. Park, C. In other (people's) words: Plagiarism by university students-literature and lessons. Assess. Eval. High. Educ. 2003, 28, 471-488. [CrossRef]

18. Devlin, M.; Gray, K. In their own words: A qualitative study of the reasons Australian students plagiarize. High. Educ. Res. Dev. 2007, 26, 181-198. [CrossRef]

19. Song-Turner, H. Plagiarism: Academic dishonesty or 'blind spot' of multicultural education? Aust. Univ. Rev. 2008, 50, 39-50.

20. Rezanejad, A.; Rezaei, S. Academic dishonesty at universities: The case of plagiarism among Iranian language students. J. Acad. Ethics 2013, 11, 275-295. [CrossRef]

21. Abbas, A.; Fatima, A.; Arrona-Palacios, A.; Haruna, H.; Hosseini, S. Research ethics dilemma in higher education: Impact of internet access, ethical controls, and teaching factors on student plagiarism. Educ. Inf. Technol. 2021, 26, 6109-6121. [CrossRef]

22. Wilkinson, J. Staff and student perceptions of plagiarism and cheating. Int. J. Teach. Learn. High. Educ. 2009, 20, 98-105.

23. Bacha, N.N.; Bahous, R. Student and teacher perceptions of plagiarism in academic writing. Writ. Pedagog. 2010, 2, 251-280. [CrossRef]

24. Yazici, A.; Yazici, S.; Erdem, M.S. Faculty and student perceptions on college cheating: Evidence from Turkey. Educ. Stud. 2011, 37, 221-231. [CrossRef]

25. Songsriwittaya, A.; Kongsuwan, S.; Jitgarum, K.; Kaewkuekool, S.; Koul, R. Engineering students' attitude towards plagiarism: A survey study. In Proceedings of the ICEE, ICEER Korea: International Conference on Engineering Education Research, Seoul, Korea, 12 September 2009.

26. Sheikh, S. The Pakistan experience. J. Acad. Ethics 2008, 6, 283-287. [CrossRef]

27. Shirazi, B.; Jafarey, A.M.; Moazam, F. Plagiarism and the medical fraternity: A study of knowledge and attitudes. J. Pak. Med. Assoc. 2010, 60, 269-273.

28. Javaid, S.T.; Sultan, S.; Ehrich, J.F. Contrasting first and final year undergraduate students' plagiarism perceptions to investigate anti-plagiarism measures. J. Appl. Res. High. Educ. 2020, 13, 561-576. [CrossRef]

29. Murtaza, G.; Zafar, S.; Bashir, I.; Hussain, I. Evaluation of student's perception and behavior towards plagiarism in Pakistani universities. ActaBioethica 2013, 19, 125-130. [CrossRef]

30. Ramzan, M.; Munir, M.A.; Siddique, N.; Asif, M. Awareness about plagiarism amongst university students in Pakistan. High. Educ. 2012, 64, 73-84. [CrossRef]

31. Goodman, J.; Melkers, J.; Pallais, A. Can Online Delivery Increase Access to Education? Working Paper 22754; National Bureau of Economic Research: Cambridge, MA, USA, 2016.

32. Noreen, S.; Malik, M.A. Digital Technologies for Learning at Allama Iqbal Open University (AIOU): Investigating Needs and Challenges. Open Prax. 2020, 12, 39-49. [CrossRef]

33. Malik, M.A.; Akkaya, B. Comparing the Academic Motivation of Conventional and Distance Education Students: A Study about a Turkish University. Sir. Syed. J. Educ. Soc. Res. 2021, 4, 341-351. [CrossRef] 
34. Olt, M.R. Ethics and distance education: Strategies for minimizing academic dishonesty in online assessment. Online J. Distance Learn. Adm. 2002, 5, 1-7.

35. Ewing, H.; Anast, A.; Roehling, T. Addressing Plagiarism in Online Programmes at a Health Sciences University: A Case Study. Assessment Eval. High. Educ. 2016, 41, 575-585. [CrossRef]

36. Donald, A.; Jacobs, L.C.; Razavieh, A.; Sorensen, C.K. Introduction to Research in Education, 8th ed.; Hult Rinchart \& Wiston: New York, NY, USA, 2010.

37. Krejcie, R.V.; Morgan, D.W. Determining sample size for research activities. Educ. Psychol. Meas. 1970, 30, 607-610. [CrossRef]

38. Patton, M.Q. Qualitative Research and Evaluation Methods; Sage: Thousand Oaks, CA, 2002.

39. Weller, S.C.; Vickers, B.; Bernard, H.R.; Blackburn, A.M.; Borgatti, S.; Gravlee, C.C.; Johnson, J.C. Open-ended interview questions and saturation. PLoS ONE 2018, 13, e0198606. [CrossRef]

40. Corden, A.; Sainsbury, R. Research Participants' Views on Use of Verbatim Quotations. Social Policy Research Unit. University of York; 2005. Available online: https://www.york.ac.uk/inst/spru/pubs/pdf/verb.pdf (accessed on 1 December 2021).

41. Corden, A.; Sainsbury, R. Exploring 'Quality': Research Participants' Perspectives on Verbatim Quotations. Int. J. Soc. Res. Methodol. 2006, 9, 97-110. [CrossRef]

42. Power, L.G. University students' perceptions of plagiarism. J. High. Educ. 2009, 80, 643-662. [CrossRef]

43. Dawson, J. Plagiarism: What's Really Going On? In TL Forum 2004. Seeking Educational Excellence; Murdoch University: Perth, Australia, 2004.

44. Hoodbhoy, P. Pakistan's Higher Education System-What Went Wrong and How to Fix It. Pak. Dev. Rev. 2009, 48, 581-594. [CrossRef]

45. Hart, L.; Morgan, L. Academic integrity in an online registered nurse to baccalaureate in nursing program. J. Contin. Educ. Nurs. 2010, 41, 498-505. [CrossRef]

46. Howard, R.M. Forget about Policing Plagiarism: Just Teach. The Chronicle of Higher Education, B24. Available online: https:/ / abacus.bates.edu/cbb/events/docs/Howard_ForgeT.pdf (accessed on 16 November 2001).

47. Aduke, A.F. Time Management and Students Academic Performance in Higher Institutions, Nigeria-A Case Study of Ekiti State. Int. Res. Edu. 2015, 3, 1-12. [CrossRef]

48. Ehrich, J.; Howard, S.J.; Mu, C.; Bokosmaty, S. A Comparison of Chinese and Australian University Students' Attitudes Towards Plagiarism. Stud. High. Educ. 2016, 41, 231-246. [CrossRef]

49. Arum, R. Improve relationships to improve student performance. Phi. Delta. Kappan. 2011, 93, 8-13. [CrossRef]

50. Jamil, S.; Majoka, M.I.; Kamraan, U. Analyzing Common Errors in English Composition at Post-graduate Level in Khyber Pakhtunkhaw (Pakistan). Bull. Educ. Res. 2016, 38, 53-67.

51. Kharma, N. A Contrastive Analysis of the Use of Verb Forms in English and Arabic; Juliius Groos Verlog: Heidelberg, Germany, 1983.

52. Razera, D. Awareness, Attitude and Perception of Plagiarism among Students and Teachers at Stockholm University. Master's Thesis, Stockholm University, Stockholm, Sweden, 2011. Available online: https://www.diva-portal.org/smash/get/diva2: 432681/FULLTEXT01.pdf (accessed on 1 December 2021).

53. Wheeler, G. Culture of minimal influence: A study of Japanese university students' attitudes toward plagiarism. Int. J. Educ. Integr. 2014, 10, 44-59. [CrossRef]

54. Horváth, J. A szakmai közösségnek tudnia kell ezekről a problémákról": A plágium kezelése a magyar egyetemi gyakorlatban" ["The academic public needs to know about these problems": Dealing with plagiarism in Hungarian higher education]. Iskolakultúr 2012, 22, 96-110.

55. Leask, B. Plagiarism, cultural diversity and metaphor-Implications for academic staff development. Assess. Eval. High. Educ. 2006, 31, 183-199. [CrossRef]

56. Bashir, S.; Malik, M.A. Caring Behavior of Teachers: Investigating the Perceptions of Secondary School Teachers and Students in Lahore. Int. J. Innov. Teach. Learn. 2020, 6, 63-78. 